DOI: 10.12957/demetra.2015.16072

\title{
Alimentação, comida e cultura: o exercício da comensalidade
}

\section{Food and culture: the exercise of commensality}

Romilda de Souza Lima'

José Ambrósio Ferreira Neto²

Rita de Cássia Pereira Farias ${ }^{3}$

1 Universidade Estadual do Oeste do Paraná. Centro de Ciências da Saúde e Centro de Ciências Sociais Aplicadas. Grupo de Pesquisa em Segurança Alimentar e Nutricional. Francisco Beltrão - PR, Brasil.

${ }^{2}$ Universidade Federal de Viçosa. Centro de Ciências Agrárias, Departamento de Economia Rural. Viçosa- MG, Brasil.

${ }^{3}$ Universidade Federal de Viçosa. Centro de Ciências Humanas, Letras e Artes, Departamento de Economia Doméstica. Viçosa- MG, Brasil.

Este trabalho é um pequeno recorte do capítulo teórico da tese de doutorado, intitulada: "Práticas alimentares e sociabilidades em famílias rurais da Zona da Mata Mineira: mudancas e permanências". A tese está em fase de conclusão, a ser defendida até novembro de 2015 pelo programa de doutorado em Extensão Rural da Universidade Federal de Viçosa-MG.

Correspondência / Correspondence

Romilda de Souza Lima

E-mail: romislima2@gmail.com

\section{Resumo}

Este artigo, no formato de ensaio, apresenta uma reflexão conceitual sobre alimentação e cultura. Neste contexto, insere-se a discussão sobre a comensalidade e sua importância ao longo do processo histórico e social dos povos, apresentando o uso do fogo como importante fator cultural e social que potencializou a agregação, e também como peça central nas mudanças das práticas alimentares. Discutem-se, ainda, as dinâmicas de comensalidade, as práticas alimentares adotadas na contemporaneidade em suas conexões com o tradicional e o moderno. Traz a abordagem, a partir de alguns autores da antropologia e da sociologia da alimentação, a diferença entre alimento e comida - quando se trata de aspectos fisiológicos e automáticos, como atendimento à sobrevivência humana e o sentido dado pelo viés cultural quando comer adquire também importância simbólica. Portanto, é na compreensão cultural e social da comida que este artigo se fundamenta. Trata-se daquele sentido em que, através das regras socialmente estabelecidas, criam-se vínculos com quem come e com as demais dinâmicas que envolvem a comensalidade.

Palavras-chave: Comensalidade. Práticas Alimentares. Cultura.

\section{Abstract}

This article, in an essay format, presents a conceptual reflection on food and culture. In this context, it is part of the discussion about the edibility and its importance throughout the historical and social process of people, with the use of fire as a major cultural and social factor that enhanced the aggregation, as well 
as the centerpiece in changing eating habits. We discuss also the dynamics of table fellowship, food practices in the contemporary in its connections with the traditional and the modern. It brings the approach from some authors of anthropology and sociology of food, the difference between feeding and food when it comes to physiological and automatic aspects such as compliance with human survival and the meaning of the cultural bias, which is when eating also acquires symbolic importance. Therefore, it is the cultural and social understanding of food that this article is based upon. It is that sense that, through socially established rules, it creates links to the eater and other dynamics involving commensality.

Key words: Commensality. Food Practices. Culture.

\section{Introdução}

Muito além de uma atitude biológica, a alimentação assume também um comportamento cultural. Biológica, por uma questão de sobrevivência, sendo um fator insubstituível para a manutenção da vida e condição sine qua non para todos os seres humanos. Relaciona-se diretamente à vitalidade do indivíduo, à necessidade fisiológica de ingerir nutrientes capazes de manter o corpo em funcionamento, sendo, sob esse aspecto, um comportamento relativo à natureza humana. $\mathrm{O}$ que ingerir e as quantidades a serem ingeridas para suprir as necessidades variam de uma pessoa para outra, de acordo com fatores como idade, altura, peso, tipo de atividade, quadro clínico, entre outros.

Corresponder a uma atitude natural e de caráter instintivo não torna, necessariamente, o ato de alimentar-se algo consciente sob o aspecto nutricional, porque nem todos os indivíduos conhecem a composição dos alimentos. Aqueles que conhecem nem sempre pensam a respeito disso ao realizarem as refeições cotidianas, aspecto que foi tratado por Harris ${ }^{1}$ e por García ${ }^{2}$.

\section{O processo de escolhas alimentares}

De Garine, ${ }^{3}$ ao resgatar o pensamento de Margaret Mead, ${ }^{4}$ destaca que as escolhas alimentares dos seres humanos estão relacionadas às possibilidades de alimentos disponibilizados pelo meio e ao potencial técnico que possuem. 
La supervivencia de un grupo humano exige por supuesto que su régimen alimenticio satisfaga las necesidades nutritivas. No obstante, el nivel de satisfacción de estas necesidades, cuya definición sigue siendo controvertida, varía cualitativa y cuantitativamente de una sociedad a otra. También cambia en el interior de cada una según la categoría de edad, el sexo, el nivel económico y otros $\operatorname{criterios}^{3}(p .4)$."

De acordo com Contreras \& Gracia, ${ }^{5}$ e Woortmann, ${ }^{6}$ as escolhas alimentares, que são as formadoras dos hábitos alimentares, constituem parte da totalidade cultural. Para Contreras \& Gracia, ${ }^{5}$ pode-se afirmar que "somos o que comemos", tanto no aspecto fisiológico como no espiritual, ao "incorporar" psicossocialmente os elementos culturais daquilo que ingerimos, que podem ser desde elementos ligados à espiritualidade como à memória afetiva. Pela mesma razão, defendem que "comemos o que somos".

Comemos aquilo que nos faz bem, ingerimos alimentos que são atrativos para os nossos sentidos e nos proporcionam prazer, enchemos a cesta de compras de produtos que estão no mercado, e na feira, e nos são permitidos por nosso orçamento, servimos ou nos são servidas refeições de acordo com nossas características: se somos homens ou mulheres, crianças ou adultos, pobres ou ricos. E escolhemos ou recusamos alimentos com base em nossas experiências diárias e em nossas ideias dietéticas, religiosas ou filosóficas ${ }^{5}$ (p. 16).

Em percepção semelhante, Woortmann, ${ }^{6}$ em estudos sobre dimensões sociais da comida entre os camponeses, defende a "comida" para este grupo como sendo uma "categoria cultural nucleante" que se articula a "trabalho" e a "terra", e que as escolhas alimentares que incluem alimentos proibidos, permitidos e os preferidos estão ligadas às dimensões de gênero, memória, família, identidade e também religião, etc.

DaMatta ${ }^{9}$ defende que "o jeito de comer define não só aquilo que é ingerido como também aquele que ingere" (p. 56). Pode-se afirmar, portanto, que comer é mais do que apenas um ato de sobrevivência; é também um comportamento simbólico e cultural.

É na compreensão cultural e social da comida que este ensaio se fundamenta. Trata-se daquele sentido em que, através das regras socialmente estabelecidas, criam-se vínculos com quem come,

* Obviamente, a sobrevivência dos seres humanos exige que sua dieta atenda às necessidades nutricionais. No entanto, o nível de satisfação dessas necessidades, cuja definição é controversa, irá variar tanto em qualidade como em quantidade de uma sociedade para outra. Essa variação se relaciona às categorias "idade", "sexo", "condição econômica" e outros critérios (tradução nossa).

* Conhecido aforismo proferido pelo filósofo alemão Ludwig Feuerbach7, na obra: O mistério do sacrifício ou o homem é o que ele come. Também Brillat-Savarin8 escreveu, em seu tratado sobre "A fisiologia do gosto": "Dizeme o que comes e te direi quem és". Os dois aforismos são muito utilizados por aqueles que escrevem sobre alimentação. 
com o que se produz e com as demais dinâmicas que envolvem a comensalidade.*** Ou no sentido dado por Cândido: ${ }^{10}$

Qualquer que seja a posição do alimento, é sempre acentuada a sua importância como fulcro de sociabilidade - não apenas do que se organiza em torno dele (sistemas de trabalho, distribuição, etc) mas daquelas em que ele aparece como expressão tangível dos atos e das intenções ${ }^{10}(p .30)$.

A diferença entre o alimento como fator biológico e o alimento como cultura é discutida principalmente por Montanari, ${ }^{11}$ Delormier et al., ${ }^{12}$ DaMatta, ${ }^{9,13}$ Maciel,${ }^{14}$ Ishige, ${ }^{15}$ Silva Mello, ${ }^{16}$ Crotty, ${ }^{17}$ De Garine, ${ }^{3}$ Câmara Cascudo ${ }^{18}$ e Woortmann. ${ }^{19}$

Embora o ato de comer acompanhe a espécie humana desde sua origem, o termo "alimento" surgiu, segundo Poulain, ${ }^{20}$ por volta do ano 1120, mas seu significado atual somente foi utilizado a partir do século XVI, quando passou a substituir a expressão "carne" e esta passou a se referir apenas à carne tal qual a conhecemos, ou seja, a dos animais comestíveis. O autor explica que, anteriormente, a expressão "carne" era utilizada para se referir a tudo o que era bom para manter a vida, fossem alimentos cárneos ou não. Para esse autor, um alimento deve possuir essas quatro qualidades: nutricionais, organolépticas, higiênicas e simbólicas. Sobre as simbólicas, ele destaca:

Para ser um alimento, além das três primeiras características de qualidade, um produto natural deve poder ser o objeto de projeções de significados por parte do comedor. Ele deve poder tornar-se significativo, inscrever-se numa rede de comunicações, numa constelação imaginária, numa visão de mundo ${ }^{20}$ (p. 240).

Crotty $^{17}$ apud Delormier et al. ${ }^{12}$ defende que a prática alimentar abrange duas acepções: aquela posterior à ingestão do alimento e que está relacionada ao universo da biologia (fisiologia e bioquímica); e aquela anterior à ingestão. Esta última está relacionada às questões culturais e sociais, ou seja, à natureza social do comer. Segundo a autora, no campo da disciplina da Nutrição, dá-se pouco valor a este último aspecto, até mesmo devido a seus objetivos técnico-científicos. Concordando com a percepção de Crotty, ${ }^{17}$ Delormier et al. ${ }^{12}$ defendem que não considerar os aspectos sociais e culturais no campo de interesse representa, de certa forma, uma limitação a qualquer disciplina. Os autores analisam, ainda, que o processo de escolha alimentar, na maior parte das vezes, não se dá primeiramente pela opção nutricional, mas pelas influências do convívio social cotidiano, que podem estar presentes nas relações familiares, mas também no local de

*** Etimologicamente, comensalidade deriva do latim "comensale". Ação de comer junto, na mesma mesa. Com: “junto", e Mensa: "mesa". Implica partilhar do mesmo momento e local das refeições. Para Poulain, ${ }^{20}$ a comensalidade estabelece e reforça a sociabilidade. "É pela cozinha e pelas maneiras à mesa que se produzem as aprendizagens sociais mais fundamentais e que uma sociedade transmite e permite a interiorização de seus valores. A alimentação é uma das formas de se tecer e se manter os vínculos sociais” (p. 182). 
trabalho, na escola e em outros locais de convivência que permitem trocas e ajudam a moldar o sistema alimentar dos indivíduos.

A atribuição de status simbólico dado ao alimento e ao ato de comer é definida, segundo alguns autores, pela diferença semântica entre "comida" e "alimento". DaMatta, ${ }^{13}$ ao estudar a comida brasileira, defende que toda substância nutritiva é um alimento, mas nem todo alimento é comida. Alimento, aponta o autor, é universal e geral, é o que o indivíduo ingere para se manter vivo; já a comida ajuda a situar uma identidade e definir um grupo, uma classe, uma pessoa. "Temos o alimento e temos a comida. Comida não é apenas uma substância alimentar, mas é também um modo, um estilo e um jeito de alimentar-se" ${ }^{\prime 9}$ (p. 56). Em uma aproximação a DaMatta, ${ }^{13}$ Woortmann ${ }^{19}$ aponta "comida" como sendo o oposto de mantimento, embora derive dele, pois comida é a transformação do mantimento através da culinária.

Neste sentido, comer proporciona uma relação de intimidade com o ser humano, pois há o investimento psicossocial no processo de escolha dos alimentos. O próprio processo de ingerir demonstra a intimidade existente entre a comida e o corpo, considerando que trata daquilo, que, segundo Mintz, ${ }^{21}$ "é colocado para dentro do corpo" (p. 31). O autor defende que "nenhum outro comportamento não automático se liga de modo tão íntimo à nossa sobrevivência”. Corroborando esse pensamento, Câmara Cascudo ${ }^{18}$ defende que é "inútil pensar que o alimento contenha apenas os elementos indispensáveis à nutrição. Contém substâncias imponderáveis e decisivas para o espírito, alegria, disposição criadora, bom humor" (p. 348).

Maciel ${ }^{14}$ também compartilha a ideia de diferenciação entre "comida" e "alimento", ao reconhecer a junção entre natureza e cultura quando se trata de alimentação humana, pois poucas horas após o nascimento, instintivamente, a criança chora em busca do leite materno. No entanto, a amamentação em humanos é um ato também cultural, considerando que o recém-nascido, ao ser amamentado, experimenta a sensação de aconchego, favorecendo o vínculo entre mãe e filho, e ainda o prazer de comer. A criança gosta do sabor do leite e não o rejeita. O leite é assim, alimento e comida - natureza e cultura.****

Comida é, assim, o alimento transformado pelas representações sociais e culturais. É o que sugere também Montanari, ${ }^{11}$ para quem, diferentemente das outras espécies animais, o homem aproveita os alimentos que encontra na natureza e também cria a própria comida usando os alimentos básicos encontrados, transformando-os pelo uso do fogo e recorrendo às práticas tecnológicas que se desenvolvem nas cozinhas. "Os valores de base do sistema alimentar se definem como resultado e representação de processos culturais que preveem a domesticação, a transformação e a reinterpretação da natureza” (p. 15). O consumo dos alimentos também é tratado

**** Silva Mello, ${ }^{16}$ Sandre-Pereira, ${ }^{22}$ Mead, ${ }^{4}$ Bosi \& Machado ${ }^{23}$ são outros autores que discutem a questão sobre amamentação e cultura. 
como cultura pelo autor, uma vez que o homem escolhe o que comer baseado em critérios de ordem econômica, nutricional, preferências, mas também em simbologias atribuídas ao alimento portanto, comida. Por essas razões, "a comida se apresenta como elemento decisivo da identidade humana e um dos mais eficazes instrumentos para comunicá-la" (p. 16). A natureza produz os alimentos, mas a cultura faz surgir códigos importantes, como por exemplo, as diferentes opções de cardápios, as receitas, os hábitos, que por sua vez se relacionam ao paladar, ao prazer relacionado às propriedades organolépticas dos alimentos e, sobretudo, ao prazer da degustação.

\section{A importância social e cultural do uso do fogo e sua relação com a comensalidade}

O valor cultural do alimento se fortalece a partir da descoberta do fogo e do início do processo de cozimento dos alimentos. Os pesquisadores das Ciências Sociais que primeiramente deram ênfase ao papel fundamental do fogo na transformação do alimento, atribuindo-lhe uma função cultural para além da biológica, foram: Claude Lévi-Strauss, ${ }^{24}$ Jean Anthelme Brillat-Savarin, ${ }^{8}$ Richard Wrangham ${ }^{25}$ e Massimo Montanari. ${ }^{11}$

Segundo Montanari, ${ }^{11}$ para os seres humanos, a comida é cultura e não apenas pura natureza, devido à adoção - como parte essencial de suas técnicas - dos modos de produção, de preparação e de consumo de alimentos, bem como o conhecimento sobre plantas próprias para consumo. Para o autor, o uso do fogo é fundamental na transformação do alimento bruto em produto cultural, em comida. Quanto a esta percepção, Lévi Strauss ${ }^{24}$ discute, em “O cru e o cozido”, como o uso do fogo permitiu de certa forma o homem passar do estado da natureza - ao se referir à ingestão do alimento de caça ou coleta na forma crua - para o estado da cultura, a partir da transformação do alimento em cozido. Numa analogia à linguagem verbal dos grupos, ele propõe explicar a relação natureza-cultura com a linguagem da comida. Nessa explicação, o autor, em seu artigo denominado "O triângulo culinário", afirma, conferindo status de linguagem universal à comida: “assim como não existe sociedade sem linguagem, não existe nenhuma que, de um modo ou de outro, não cozinhe pelo menos alguns de seus alimentos" (p. 25). O triângulo culinário proposto pelo antropólogo se forma pelo cru, pelo cozido (assado e fervido) e pelo apodrecido.

Está claro que em relação à cozinha, o cru constitui o polo não marcado e que os dois outros, o são acentuadamente, mas em direções opostas: com efeito, o cozido é uma transformação cultural do cru, enquanto que o apodrecido é uma transformação cultural dele. Subjacente ao triângulo primordial, há, portanto, uma dupla oposição entre: elaborado/não elaborado de um lado e, entre: cultura/natureza, de outro. Sem dúvida alguma, estas noções constituem formas vazias: nada nos ensinam sobre a cozinha de tal ou tal sociedade particular, uma vez que apenas a observação pode nos dizer o que cada um entende por "cru", "cozido" e "apodrecido", e uma vez que pode se supor que não será a mesma coisa para todas"24 (p. 25). 
Em uma escala de relevância cultural, o cru está na base mais simples da escala; na sequência viria o assado, ocupando segunda posição, pois necessita apenas do fogo. Os mais elaborados são, assim, fervido ou ensopado, que por necessitarem de maior envolvimento humano e de uma vasilha com água, estão num patamar de elaboração mais complexo e, portanto, numa escala de maior relevância cultural.

O fogo possui papel importantíssimo na discussão da comida como cultura desde os primórdios da humanidade. Tanto assim que Lévi-Strauss analisou a mitologia dos povos ameríndios e seu "mundo" culinário buscando traduzir, entre outras questões, os mitos sobre a origem do fogo a partir da representação desse grupo. Após Lévi-Strauss, surgiram outros estudos destacando a importância do fogo na prática de cozinhar, e um dos mais recentes é do antropólogo Wrangham, ${ }^{25}$ que também defende a descoberta do fogo e o cozimento como sendo definidores da humanidade e responsáveis por diferenciar os humanos dos macacos, originando o gênero Homo. Semelhante afirmação é feita por García ${ }^{26 .}$ :

La conquista del fuego supuso (de manera metafórica) la separación definitiva del mundo de los seres vivos en dos grupos: de un lado quedaron los hombres, de otro los demás animales. El fuego nos transformó en humanos. La domesticación del fuego supuso, em definitiva, un impulso decisivo en la historia humana, un impulso fecundador que permitió que se produjeran nuevos avances que a su vez abrieron la vía a otros progresos, generando una reacción em cadena que ha desembocado en el complejo y tecnificado mundo $\operatorname{actual}^{26}(p .167){ }^{* * * * *}$

Cozinhar aumentou o valor da comida. Assim, o uso do fogo alterou fisicamente o corpo humano, reduzindo o aparelho digestivo, e aumentou o tamanho do cérebro, mas também alterou o uso do tempo e a vida social. O impacto recai, ainda, sobre as relações com a natureza, que segundo Wrangham, ${ }^{25}$ "transformou-nos em consumidores de energia externa e criou um organismo com uma nova relação com a natureza, dependente de combustível” (p. 7). O cozimento facilitou a ingestão e a digestão de muitos alimentos, como os cereais, por exemplo, da mesma forma algumas leguminosas e a maior parte dos tubérculos.

"As pessoas não precisam cozer sua comida, elas o fazem por razões simbólicas, para mostrar que são homens e não animais" (Leach ${ }^{27}$ apud Wrangham, ${ }^{25}$ p. 15). Afinal, somos os únicos animais capazes de cozinhar o próprio alimento. Por outro lado, não se pode afirmar que ingerir alimento cru não possua característica cultural, pois como argumenta Giard:28 "mesmo cru e colhido

***** A conquista do fogo propiciou (de maneira metafórica) a separação definitiva do mundo dos seres vivos em dois grupos: o dos homens e os dos outros animais. O fogo nos transformou em humanos. A domesticação do fogo gerou um impulso decisivo na história humana, um impulso que permitiu a produção de novos avanços que abriram portas para novos progressos, gerando uma reação em cadeia que desembocou no complexo e tecnificado mundo atual. (Tradução nossa). 
diretamente da árvore, o fruto já é um alimento culturalizado, antes de qualquer preparação e pelo simples fato de ser tido como comestível" (p. 232). Para a autora, a noção de alimento comestível irá variar de um grupo a outro, ou seja, ele é definido pela cultura, questões que vimos anteriormente neste ensaio.

Há outro fator muito importante a se destacar, o qual se pode atribuir à descoberta do fogo, que é o fato de ter propiciado às pessoas e aos grupos juntarem-se em torno dele para se aquecer, mas também para preparar a comida, distribuí-la e ingeri-la. Facilitou-se, assim, o estabelecimento de relações de comensalidade que, com o tempo, foram se tornando encontros cotidianos e transformando-se em uma atividade socializadora.

Conforme argumentam Fladrin \& Montanari, ${ }^{29}$ independentemente da forma e das diferenças nas normas de comportamento existentes em cada sociedade, o fato é que "a comensalidade é percebida como um elemento 'fundador' da civilização humana em seu processo de criação" (p. 109) e, para Carneiro, ${ }^{30}$ a comensalidade se constitui em "um complexo sistema simbólico de significados sociais, sexuais, políticos, religiosos, éticos, estéticos, etc.” (p. 2).

Ao redor do fogo é possível se aquecer, preparar os alimentos e a comida, mas também estabelecer o diálogo. Segundo García, ${ }^{26}$ nos primórdios da humanidade, os encontros diários dos grupos se davam em torno do fogo para trocar experiências do dia e traçar estratégias de caça, por exemplo. Para Wrangham, ${ }^{25} \mathrm{o}$ advento do fogo mudou a maneira de nossos ancestrais se relacionarem. Passava-se mais tempo junto se aquecendo e alimentando-se em grupo. No volume um da primeira obra dirigida por Philippe Ariès \& Georges Duby, ${ }^{31}$ História da vida privada, a importância do fogo é destacada logo no início do capítulo, de autoria de Yvon Thébert, ${ }^{32}$ que trata da vida privada e da arquitetura doméstica na África Romana. Nas habitações não havia chaminé nem fogões, e sim lareiras, "cuja fumaça saía por um buraco no teto e constituía paradoxalmente um dos celebrados prazeres da rude existência rural, quando a neve cobria os campos" (p. 303).

Segundo Flandrin \& Montanari, ${ }^{29} \mathrm{o}$ uso do fogo permitiu ao homem alimentar-se em conjunto, inicialmente ao seu redor em áreas externas, e com o passar dos anos, com a criação do espaço social alimentar, nos ambientes domésticos (a cozinha e a sala de jantar) e, na sequência, com a criação de espaços externos às residências (restaurantes, lanchonetes etc.). Assim, a comida, que é o alimento transformado pela cultura, passa a possuir também a função agregadora para os seres humanos. A essa função se dá o nome de "comensalidade", que tem como significado a capacidade de estabelecer relações de sociabilidade importantes, pois implica reunir as pessoas em torno da mesa. Ou seja, enquanto come, o grupo tem também a oportunidade de dialogar e trocar experiências do cotidiano.

Para Fischler, ${ }^{33}$ a comensalidade é uma das características mais significantes no que se refere à sociabilidade humana, relacionando-se não apenas à ingestão de alimentos, mas também aos modos do comer, envolvendo hábitos culturais, atos simbólicos, organização social, além do 
compartilhamento de experiências e valores. Nesse sentido, Woortmann ${ }^{19}$ esclarece que, na cultura brasileira, "refeição" é considerada um ato social e que, portanto, deve ser feita em grupo para ser percebida efetivamente como uma refeição. Também em nossa cultura, segundo o autor, criamos significados diferentes para essa ação, como comer cotidianamente e comer em eventos especiais, comer em casa e comer fora de casa.

O caráter simbólico-ritual do comer se expressa claramente no hábito de convidar pessoas para jantar em nossa casa, no "jantar fora" em determinadas ocasiões ou no "almoço de domingo". Nessas, e em outras ocasiões análogas, há mais em jogo que necessidades nutricionais. Não convidamos pessoas para jantar em nossa casa para alimentá-las, enquanto corpos biológicos, mas para alimentar e reproduzir relações sociais, isto é, para reproduzir o corpo social, o que supõe que sejamos em troca convidados a comer na casa do nosso convidado. O que está em jogo é o princípio da reciprocidade e da comensalidade. A presença da comida é, contudo, central, reconstruindo-se necessidades biológicas em necessidades sociais ${ }^{19}(p .3)$.

Em semelhante percepção, Algranti ${ }^{34}$ aponta que há registros de que, desde o período colonial no Brasil, a reunião familiar durante as refeições, pelo menos uma vez ao dia, se tornou um costume que se perpetuou nas famílias rurais, bem como nas urbanas. E segundo Giard, ${ }^{28}$ momentos como esses demarcavam as relações sociais e afetivas entre os membros da família e também o desenvolvimento do gosto alimentar. Neste sentido, "o comer" é um ato tanto social quanto político e envolve costumes, diálogos, usos, sabores, odores e até mesmo as etiquetas, que correspondem às maneiras de comer, que são aprendidas no próprio processo de comensalidade que se dá nos grupos.

É preciso ressaltar, no entanto, que nem todas as culturas apreciam comer em conjunto. Assim, não se pode considerar como regra os preceitos da comensalidade. Como nos mostra Geertz ${ }^{35}$ sobre a cultura balinesa, em que comer é considerado uma atividade que gera repulsa: "[...] mas até comer é visto como uma atividade desagradável, quase obscena, que deve ser feita apressadamente e em particular, devido à sua associação com a animalidade" (p. 190).

\section{O local do fogo e da prática da comensalidade na arquitetura doméstica}

Independentemente de comer ou não em grupo, há em praticamente toda cultura o local onde o fogo e o calor se fazem presentes. Na sociedade ocidental, o local do fogo em uma habitação é principalmente a cozinha, que primeiramente era anexa à casa, e o equipamento que o representa é o fogão. A cozinha, segundo Flandrin, ${ }^{36}$ surge em função das transformações nos costumes sociais ao longo do tempo. Assim, o prazer no comer e beber juntos foi se modificando concomitantemente às mudanças nas sociedades. Avanços tecnológicos e encontros com outras culturas favoreceram a 
vida e a criação de espaços internos à casa, destinados à comensalidade, por exemplo. A cozinha, que antes era compartilhada com várias pessoas ao redor do pátio, passa a ser parte interna de cada habitação. O espaço privado está associado à intimidade e ao refúgio, em contraste a um espaço público do qual o cotidiano doméstico das famílias vai se afastando aos poucos. As refeições, que eram feitas ao ar livre ou em locais de fácil acesso, passam a ser feitas em casas de alvenaria que possuem portas da rua que ficam fechadas, impedindo o acesso a qualquer pessoa que chegar, exceto por convite dos donos da casa.

Mesmo que inicialmente a cozinha tenha se mantido distante dos outros cômodos, ocupava lugar de destaque nas características habitacionais, das mais simples às mais requintadas, desde o período Colonial no Brasil, conforme aponta Lemos ${ }^{37}$ em seu estudo sobre as casas urbanas e rurais brasileiras. "Em Portugal até há pouco tempo e no Brasil Colonial, sempre se chamou a moradia de 'fogo' ou 'fogão'. Qualquer recenseamento dizia que determinada cidade possuía tantos habitantes em tantos 'fogos"' (p. 11).

As cozinhas do período de colonização no Brasil estavam sempre voltadas para o exterior da casa, em seus fundos, ficando distantes dos cômodos de dormir, mantendo-os livres do cheiro de fumaça e de gordura. Por não haver água encanada na época, a cozinha se localizava muitas vezes na área externa da habitação. ${ }^{38,39}$ Para facilitar o uso desse espaço e para manter a cozinha próxima, a alternativa foi criar uma subdivisão. ${ }^{40}$ Assim surgiu, no século XIX, a "cozinha suja" (onde se preparavam carnes, doces e frituras), que permanecia fora da casa, enquanto a "cozinha limpa” se acoplava à residência, e onde se preparaam o café, os bolos, as saladas.

Segundo Abdala, ${ }^{41}$ o espaço da cozinha nas casas do período colonial em Minas Gerais, que perdurou pelo século XIX, era amplo, bem ventilado, e o fogão a lenha, feito de barro ou de pedra sabão, ocupava local de destaque. Era ainda um espaço íntimo, não sendo permitida a entrada de estranhos.

A sala de jantar surgiu no final do século XVIII e início do XIX. Antes disso, qualquer cômodo da habitação servia a esta finalidade, mesmo nos imensos castelos, onde o conforto era pequeno, apesar dos grandes espaços. Ambos os cômodos se constituíram, ao longo da História, nos espaços principais destinados à comensalidade. ${ }^{18}$ E era também um espaço, assim como a cozinha, em que as mulheres precisavam provar seus dotes como donas de casa, sua capacidade de receber visitas, atividade que fazia parte dos saberes transmitidos das mães para as filhas, de forma que por mais simples que fossem, as salas de jantar refletiam a personalidade da dona da dona da casa. ${ }^{38}$

As modificações nos tamanhos e estrutura desses espaços domésticos nos tempos atuais sinalizam que os arranjos destinados a esta atividade estão sendo redefinidos socialmente, mas não desapareceram. No sul do Brasil ainda é comum haver, nos dias de hoje, os fogões a lenha, mesmo nas residências urbanas do interior. Diferentemente da Região Sudeste, destacando-se Minas Gerais, em que o fogão a lenha é, em sua maioria, feito de alvenaria, nos estados do sul, 
eles são no estilo industrial de ferro esmaltado. Nos dias frios, é em torno dele que a família e os amigos se reúnem para cozinhar e degustar o pinhão, por exemplo, acompanhado de vinho e muita conversa. Em Minas, o fogão a lenha está presente em quase todas as habitações rurais e presume-se que seu uso é constante no preparo da comida no dia a dia. Para a tese de doutorado da qual faz parte o presente ensaio, a permanência e o uso do fogão a lenha nos dias atuais, nas áreas rurais pesquisadas, são tema de investigação empírica.

No meio rural brasileiro a cozinha, e as relações que nela se estabelecem ocuparam diferentes lugares ao longo do tempo, mas sempre tiveram papel importante, como nos mostram Luís da Câmara Cascudo ${ }^{18}$ e Gilberto Freyre. ${ }^{42}$

Freyre $^{42}$, ao tratar das características das casas do período dos engenhos de cana, explica que havia diferenças entre as cozinhas existentes nas casas-grandes de sítios, sobrados, assobradadas de subúrbio com aquela da casa de engenho. Nestas últimas, informa o autor, a cozinha foi mais importante. Essas diferenças se refletiam inclusive no tamanho da mesa destinada às refeições e que abrigavam quem chegasse para almoçar.

Viajantes e mascates, além dos compadres que nunca faltavam, dos papa-pirões, os parentes pobres, do administrador, do feitor, do capelão, dos vaqueiros, das visitas de passar o dia: famílias inteiras que vinham de outros engenhos em carro de boi. Eram mesas de jacarandá às vezes de seis, oito metros de comprimento como as que ainda conhecemos na casa-grande - vasto sobrado rural do engenho Noruega. ${ }^{42}(p .143)^{* * * * * *}$

O autor esclarece que as mesas grandes - geralmente de cinco por dois metros -, para receber famílias enormes, eram comuns nas casas grandes de sítios e nos sobrados, mas o que ocorria é que nas cidades e subúrbio o modo de vida era mais retraído e sem muita movimentação, diferentemente do que ocorria nas casas de engenho, já que aí "se recebia o viajante a qualquer momento com bacia de prata, toalha de linho, um lugar à mesa, uma rede ou uma cama para dormir"42 (p. 144).

No entanto, nem sempre o móvel "mesa” era ou é utilizado. Comer assentado no chão faz parte da cultura indígena e também oriental. Os índios sentam-se diretamente no solo nu ou em esteiras, e os orientais sobre tapetes, nos informa Câmara Cascudo. ${ }^{18}$ Segundo o autor, no Brasil colonial os pobres também comiam dessa maneira, o que fez surgir o termo "comida de esteira". Os menos pobres comiam em mesa de madeira. "A história da alimentação na esteira decorre precisamente da herança cabocla, do escravo negro, dos mestiços humildes" (p. 794). Mesmo entre os ricos, no século XIX a mesa existia, mas era improvisada, feita em tábuas aplainadas, na maioria das vezes.

****** Este engenho foi retrato na forma de gravura aquarelada, 1933, por Cícero Dias. A aquarela compõe o livro Casa-Grande $\mathcal{E}^{2}$ Senzala, de Gilberto Freyre ${ }^{43}$ (1ํㅡomo) como documento anexo ao livro e disposto em dobradura. 
Apesar de ser um objeto frequente usado como apoio para pratos, copos, bebidas e vasilhames com as comidas, durante as refeições, nas discussões antropológicas e sociológicas importa principalmente seu sentido figurado relativo ao "comer junto", independentemente de ser assentado ao chão, no sofá, ou em torno de uma mesa de madeira ou de ferro.

Marcel Mauss, ${ }^{44}$ em seu Ensaio sobre a Dádiva, cita a "Távola Redonda" das crônicas de Artur, mesa cujo formato circular tinha o objetivo simbólico de ajudar seus cavaleiros a viver em harmonia, pois viviam em disputas e alimentando inveja entre si. A ideia era que, ao se sentarem ao seu redor, se reconhecessem como iguais, já que nela não havia local de destaque ou de superioridade.

Os bretões, as Crônicas de Artur, contam de que maneira o rei Artur, com a ajuda de um carpinteiro da Cornualha, inventou esta maravilha de sua corte: a "Távola Redonda" milagrosa em torno da qual os cavaleiros não mais se bateram. Antes, por "sórdida inveja", em escaramuças estúpidas, duelos e homicídios ensanguentavam os mais belos festins. O carpinteiro disse a Artur: "Farei uma mesa muito bela, junto à qual poderão sentar-se mil e seiscentos ou mais, e dispor-se em volta sem que ninguém seja excluído. Nenhum cavaleiro poderá travar combate, pois ali o mais graduado estará no mesmo nível que o menos graduado". Não houve "lugar de honra" e, portanto, não mais disputas. Por toda parte onde Artur transportou sua Mesa, sua nobre companhia permaneceu alegre e invencível. É assim que hoje ainda se fazem as nações, fortes e ricas, felizes e boas. Os povos, as classes, as famílias, os indivíduos poderão enriquecer, mas só serão felizes quando souberem sentar-se, como cavalheiros, em torno da riqueza comum ${ }^{44}$ (p. 314).

Importa-nos o entendimento da comensalidade no processo socializador e agregador, como aquele usado por Poulain, ${ }^{20}$ de que a comensalidade envolve comer acompanhando, que é também semelhante ao sentido atribuído por Sobal e Nelson. ${ }^{45}$ Fischler ${ }^{33}$ acrescenta um atributo de espaço a este sentido e diz que literalmente significa "comer na mesma mesa". A mesa, neste caso, podendo ser até mesmo um círculo no meio de uma floresta, a toalha posta para um picnic ou em uma roda que se forma em um evento social.

Poucas vezes um evento social ocorre sem que alguma comida ou bebida seja oferecida - os famosos coquetéis. A comida exerce um fator facilitador de relações e do diálogo nos eventos, além do poder de agregar as pessoas presentes. Nesses momentos come-se, não necessariamente por fome, mas pelo prazer do convívio, ainda que temporário, segundo Flandrin e Montanari: ${ }^{29}$

O homem civilizado come não somente (e menos) por fome, para satisfazer uma necessidade elementar do corpo, mas também (e sobretudo) para transformar essa ocasião em um momento de sociabilidade, em um ato carregado de forte conteúdo social e de grande poder de comunicação ${ }^{29}(p .108)$. 
Conforme reforçado por Giard, ${ }^{28}$ "a mesa é uma máquina social complicada, mas também eficaz: ela faz falar, 'vai-se à mesa' para confessar o que se gostaria de calar. Nada como um colóquio ao fim do jantar para adiantar os trabalhos, negócios e as coisas do coração” (p. 266). É na mesa que também se reconhecem as maneiras de comer, as diferenças entre o que se come e os modos de comer. No entanto, o modo de vida moderno tem alterado as relações de comensalidade, antes mais tradicionais e com maior constância de momentos em grupo.

Os novos modos de vida tendem a propiciar uma série de modificações nos modos de comer, nas relações de comensalidade e na identidade alimentar dos indivíduos, tanto no meio urbano quanto no meio rural, podendo interferir nos hábitos alimentares, nos horários e locais das refeições, no consumo de alimentos e na própria produção de alimentos no meio rural. Receitas de família que antes estavam nos cadernos e eram passadas por gerações, atualmente são encontradas no verso das embalagens de alimentos, na internet, em revistas e em programas de televisão; os horários de alimentação nem sempre coincidem entre os membros da família; tampouco o espaço doméstico é o único a ser usado para tal finalidade. A vida contemporânea propõe adaptações às novidades que são apresentadas constantemente. Nesse contexto, as mudanças atingem também as famílias rurais, que encontram formas de se adaptar, criando alternativas para lidar com a nova realidade.

Em função dessas questões, alguns autores analisam criticamente a tendência contemporânea de homogeneização das práticas alimentares, sendo este talvez um caminho sem volta. Essa homogeneização igualaria os comedores dos tempos modernos sob a influência da globalização, que passariam rapidamente a ter hábitos e gostos alimentares muito semelhantes. Estas considerações estão presentes nas análises de Arnaiz, ${ }^{46}$ que a partir do estudo sobre a alimentação dos espanhóis e com base nas argumentações de autores como Warde ${ }^{47} \mathrm{e}$ Germov \& Willians, ${ }^{48}$ apresenta quatro tendências para o sistema alimentar moderno:

O fenômeno da homogeneização do consumo em uma sociedade massificada; a persistência de um consumo diferencial e socialmente desigual; o incremento da oferta personalizada (pós-fordista, nos termos dos autores), avaliada pela criação de novos estilos de vida comuns, e finalmente o incremento de uma individualização alimentar, causada pela crescente ansiedade do comensal contemporâneo ${ }^{46}(p .148)$.

Fischler ${ }^{49}$ corrobora essa ideia de homogeneização, a qual denomina de "hiper-homogênea". Em função disso, citando o estudo realizado por Mennell et al., ${ }^{50}$ Fischler $^{33}$ chama a atenção para o fato de que o modo alimentar contemporâneo coloca em risco a comensalidade enquanto poder de sociabilidade, de agregação, considerando que o mundo moderno tem facilitado a individualização, inclusive no que se refere à alimentação. Exemplo disso é o número crescente de pessoas que, mesmo no ambiente doméstico, servem o seu prato e se assentam na frente da televisão ou do computador. Situações que sinalizam que outras dinâmicas têm surgido no campo da comensalidade no mundo contemporâneo. 


\section{Considerações finais}

A análise aqui apresentada nos conduz a refletir sobre os diferentes significados da comida e suas representações, e nos indica a necessidade de compreender as práticas alimentares como uma relação à qual os fatores fisiológicos, simbólicos e culturais da alimentação podem estar atrelados. Neste sentido, apreender a comida como uma atitude mais elevada do que apenas ingerir alimentos, sobretudo uma ação prazerosa, permitindo a conexão com os significados que envolvem herança cultural, memória afetiva e momentos de sociabilidade.

Aponta ainda, para o desafio dessa coexistência no mundo contemporâneo, em que o tempo dedicado à realização das refeições cotidianas se torna cada vez mais escasso e, consequentemente, reduz as refeições em família. De forma semelhante, as praticidades oferecidas pela tecnologia e o modo de vida moderno criam novos hábitos, bem como práticas mais individualizadas, que se refletem, portanto, nas escolhas alimentares.

Esta discussão sinaliza, ainda, a importância do tema da antropologia da alimentação como contribuição para os diálogos no campo da Nutrição e da Saúde.

\section{Referências}

1. Harris M. Bueno para comer. $3^{a}$ ed. Madrid: Alianza Editorial; 2011. 390 p.

2. García JL. Antropologia de la alimentación: perspectivas, desorientación contemporánea y agenda de futuro. In: Garrido Aranda A. Comida y cultura: nuevos estudios de cultura alimentaria. Córdoba: Universidad de Córdoba; 2009. p. 25-61.

3. Garine I. Alimentación, cultura y sociedad. El Correo UNESCO 1987; 40(5):4-7.

4. Mead M. Sexo e temperamento em três sociedades primitivas. São Paulo: Perspectiva; 1969. 316p.

5. Contreras J, Gracia M. Alimentação, sociedade e cultura. Rio de Janeiro: Ed. Fiocruz; 2011. 496 p.

6. Woortmann EF. Padrões tradicionais e modernização: comida e trabalho entre camponeses teutobrasileiros. In: Menasche R, organizadora. A agricultura familiar a mesa: saberes e práticas da alimentação no Vale do Taquari. Porto Alegre: Ed. UFRGS; 2007. 198 p.

7. Feuerbach L. O mistério do sacrifício ou o homem é o que ele come. 1862.

8. Brillat-Savarin JA. A fisiologia do gosto. São Paulo: Companhia das Letras; 1995. 379 p.

9. DaMatta R. O que faz o Brasil, Brasil? Rio de Janeiro: Rocco; 2001. 126 p.

10. Cândido A. Os parceiros do Rio Bonito: estudo sobre o caipira paulista e as transformações dos seus meios de vida. $6^{a}$ ed. Rio de Janeiro: Duas Cidades; 1982. 284p.

11. Montanari M. Comida como cultura. São Paulo: Senac; 2008. 207 p. 
12. Delormier T, Frohlich KL, Potvin L. Food and eating as social practice: understanding eating patterns as social phenomena and implications for public health. Sociology of Health \& Illness 2009; 31(2):215-228.

13. DaMatta R. La cultura de la mesa em Brasil. El Correo UNESCO 1987; 40(5):22-23.

14. Maciel ME. Cultura e alimentação ou o que têm a ver os macaquinhos de Koshima com BrillatSavarin? Horiz. Antropol. 2001; 7(16):145-156.

15. Ishige N. El hombre comensal. El Correo UNESCO 1987; 40(5):18-21.

16. Silva Mello A. Alimentação, intuição, cultura. $4^{a}$ ed. Rio de Janeiro: José Olympio; 1956. v. 1, 2.

17. Crotty P. The value of qualitative research in nutrition. Annual Review of Health and Social Sciences 1993; (3):109-118.

18. Câmara Cascudo L. História da alimentação no Brasil. São Paulo: Global; 2004. 954 p.

19. Woortmann K. A comida, a família e a construção de gênero. Brasília: UNB; 1985. 43 p. Série Antropologia.

20. Poulain JP. Sociologias da alimentação: os comedores e o espaço social alimentar. Florianópolis: Ed. UFSC; 2013. 285 p.

21. Mintz SW. Comida e antropologia: uma breve revisão. Revista Brasileira de Ciências Sociais 2001; 16(47):31-41.

22. Sandre-Pereira G. Os bastidores de uma escolha: o aleitamento materno no Brasil e na França. In: Menasche R, Alvarez J, Collaço J, organizadores. Dimensões socioculturais da alimentação: diálogos latino-americanos. Porto Alegre: Ed. UFRGS; 2012. p. 81-99.

23. Bosi MLM, Machado MT. Amamentação: um resgate histórico. Cadernos Escola de Saúde Pública do Ceará [Internet] 2005; 1(1). [acesso em: 10 jan. 2015]. Disponível em: http://www.aleitamento. com.br/upload\%5Carquivos\%5Carquivo1_1688.pdf

24. Lévi-Strauss C. O triângulo culinário. In: Cordier S, organizadores. Lévi-Strauss. São Paulo: Documentos; 1968. 102 p. Série L’Arc, 2.

25. Wrangham R. Pegando fogo: porque cozinhar nos tornou humanos. Rio de Janeiro: Zahar; 2010. 226 p.

26. García LJ. Una historia comestible: homínidos, cocina, cultura y ecología. Gijón: Trea SL; 2013. 270 p.

27. Leach E. Lévi-Strauss. Londres: Fontana; 1970. 153 p.

28. Giard L. Cozinhar. In: Certeau M, Giard L, Mayol P. A invenção do cotidiano II: morar, cozinhar. $11^{a}$ ed. Petrópolis: Vozes; 2012. p. 210-331.

29. Flandrin JL, Montanari M, organizadores. História da alimentação. São Paulo: Estação Liberdade; 1998. 885 p.

30. Carneiro H. Comida e sociedade: uma história da alimentação. Rio de Janeiro: Elsevier; 2003. 185 p.

31. Arriès P, Duby G. Coleção história da vida privada. v.1. São Paulo: Companhia das Letras; 1985. 635 p.

32. Thébert Y. Vida privada e arquitetura doméstica na África Romana. In: Veyne P, organizador. História da vida privada 1: do império romano ao ano mil. São Paulo: Companhia das Letras; 1990. p. 301-398. 
33. Fischler C. Commensality, society and culture. Social Science Information - 50th anniversary issue 2011; 50(3-4):528-548.

34. Algranti LM. Famílias e vida doméstica. In: Souza LM, organizadores. História da vida privada no Brasil: cotidiano e vida privada na América portuguesa. São Paulo: Companhia das Letras; 1997. p. 83-154.

35. Geertz C. A interpretação das culturas. 13ª . ed. Rio de Janeiro: LTC; 2008. 323p.

36. Flandrin JL. Formas de privatização: a distinção pelo Gosto. In: Chartier R, organizador. História da vida privada 3: da renascença ao século das luzes. São Paulo: Companhia das letras; 1990. p. 267-310.

37. Lemos C. História da casa brasileira: a casa Colonial, casas urbanas e rurais, a habitação burguesa. São Paulo: Contexto; 1996. 83p.

38. Lemos C. Cozinhas etc.: um estudo sobre as zonas de serviço da casa paulista. São Paulo: Perspectiva; 1976. $226 \mathrm{p}$.

39. Abrahão FA, Bruit HH, Abrahão EM, Leanza DA, Kassab F. Delícias das sinhás: história e receitas culinárias da segunda metade do século XIX e início do século XX. Campinas: Arte Escrita; 2007. 127 p.

40. Silva PP. Farinha, feijão e carne seca: um tripé culinário do Brasil colonial. São Paulo: Senac; 2005.149 p.

41. Abdala MC. Receita de mineiridade: a cozinha e a construção da imagem do mineiro. $2^{\mathrm{a}}$ ed. Uberlândia: EDUFU; 2007. 180 p.

42. Freyre G. Sobrados e Mucambos: decadência do patriarcado e desenvolvimento do urbano. $16^{\mathrm{a}}$ ed. São Paulo: Global; 2006. 968 p.

43. Freyre G. Casa-grande \& senzala: formação da família brasileira sob o regime da economia patriarcal. $1^{\circ}$ e $2^{\circ}$ Tomo. Rio de Janeiro: José Olympio; 1964. 1165 p.

44. Mauss M. Ensaio sobre a dádiva. In: Mauss M. Sociologia e antropologia. São Paulo: Cosac-Naify; 2003. 281-314.

45. Sobal J, Nelson MK. Commensal eating patterns: a community study. Appetite 2003; 41(2):181-190.

46. Arnaiz MG. Em direção a uma nova ordem alimentar? In: Canesqui AM, Garcia RWD. Antropologia e nutrição: um diálogo possível. Rio de Janeiro: Fiocruz; 2005. p. 147-164.

47. Warde A. Consumption, food and taste: culinary antinomies and commodity of the consumer. London: Sage Publications; 1997. 240 p.

48. Germov J, Williams L, editors. A sociology of food and nutrition. Oxford: University Press; 1999. 332 p.

49. Fischler C. Gastro-nomie et gastro-anomie. Communications 1979; (31):189-210.

50. Mennell S, Murcott A, van Otterloo AH. The sociology of food: eating, diet and culture. Londres: Sage Publications; 1992. 160 p.

Recebido: $15 / 4 / 2015$

Revisado: $12 / 5 / 2015$

Aprovado: 28/6/2015 